References

1 Royal College of Physicians. Disabling chest disease: prevention and care. $f R$ Coll Physicians Lond 1981;15:69-87.

2 Petty TL, Nett LM, Finigan MM, Brink GA, Corsello PR. A comprehensive care programme for chronic airway obstruction. Methods and preliminary evaluation of symptomatic and functional improvement. Ann Intern Med 1969;70:1109-20.

3 Cherniack RM, Handford RG, Svanhill E. Home care of chronic respiratory disease. JAMA 1969;208:821-4.

4 Goldberg DP, Hillier VF. A scaled version of the general health questionnaire. Psychol Med 1978;8:1-7.
5 Rosser RM. A set of descriptions and a psychometric scale of severity of illness: an indicator for use in evaluating the outcome of hospital care. London: University of London, 1980. (Thesis.) 6 Roper N, Logan W, Tierney AJ. Using a model for nursing. Edinburgh: Churchill Livingstone, 1983.

7 Van Dam FSAM, Linssen CAG, Couzijn AL. Evaluating 'quality of life' in cancer clinical trials. In: C Buyse ME, Staquet MJ, Sylvester RJ, eds. Cancer clinical trials. Methods and practice. Oxford: Oxford University Press, 1984:27-43.

(Accepted 12 November 1986)

\title{
Early emergency care study: the potential and benefits of advanced prehospital care
}

\author{
I W R ANDERSON， R J BLACK， I MCA LEDINGHAM， K LITTLE, C E ROBERTSON, \\ J D URQUHART
}

\begin{abstract}
Of 26358 patients taken by ambulance to the accident and emergency departments of two large hospitals, 1185 were admitted to resuscitation areas. The scope for ambulance staff to employ a range of advanced techniques at the scene of incidents was assessed by using information relating to the condition of patients when they were picked up by the ambulance and on admission, time in transit, details from hospital records, and outcome at three months. For non-survivors further assessment was made of the benefit, in terms of survival, which might have accrued had advanced techniques been used.

The results of the assessment of benefit were compared with estimates of benefit from other studies. In cases of cardiopulmonary arrest the potential to save lives was less optimistic than earlier estimates, and in cases of trauma the potential to save lives was negligible.
\end{abstract}

Victoria Infirmary, Glasgow

I W R ANDERSON, FRCS, consultant in accident and emergency medicine and surgery

Information Services Division, Scottish Health Service CSA, Trinity Park House, Edinburgh EH5 3SQ

R J BLACK, MA, research officer

J D URQUHART, MSC, principal research officer

University Department of Surgery, Western Infirmary, Glasgow

I MCA LEDINGHAM, MD, professor of intensive care

Royal Infirmary, Edinburgh

K LITTLE, MD, consultant in accident and emergency medicine and surgery

Royal Infirmary and Western General Hospital, Edinburgh

C E ROBERTSON, MRCP, consultant in accident and emergency medicine and surgery

Correspondence to Mr J D Urquhart.

Other members of the Scottish Early Emergency Care Group are:

M Begley; D Carrington, FASI; G Dickson; B Duncan, MSC; L Guest; J Hamilton; M A Heasman, FRCPE; J Hollingworth SRN; S A K Kerr, PHD; A Patel, FRCP; F Thomson; J M Wilby, FASI.

\section{Introduction}

Specialist ambulance schemes have been evaluated in a number of centres in the United Kingdom, ${ }^{1.5}$ and extended training has already been introduced by a number of ambulance services. ${ }^{6}$ There may be a good theoretical basis from which to argue that patients admitted to accident and emergency departments could benefit from advanced. training, but estimates of such benefit have so far been based on limited evidence. In previous studies the ability of ambulance staff to achieve successful outcomes without advanced training has not been fully taken into account.

This study describes patterns of illness and injury, the early $\mathbb{\mathbb { D }}$ emergency care currently provided by ambulance staff, and out- $\vec{F}$ comes for patients transported by ambulance to two accident and emergency departments serving urban and semiurban areas. These departments serve a combined catchment population which is estimated to be 0.95 million. Information from the study provides the basis for an evaluation of the scope for further intervention by ambulance staff with advanced training and the benefits, in terms of patient survival, which could be achieved. This evaluation has important implications for extended training schemes.

\section{Methods}

The study population comprised all patients taken by ambulance to the accident and emergency departments of Edinburgh Royal Infirmary and Glasgow Western Infirmary during the 12 months from 1 April 1984 to 31 March 1985. With rare exceptions children were not included in the study because they were treated in accident and emergency departments in specific $\omega$ children's hospitals.

Details of transportation times and the locations of incidents were 0 obtained from ambulance log sheets. In Edinburgh ambulance staff $\frac{D}{D}$ recorded information relating to the condition of patients when they were $\stackrel{\mathscr{P}}{+}$ picked up by the ambulance (uplift) using a descriptive system derived from 0 the triage index. ${ }^{7}$ The descriptive method used was based on observations of the patients' conscious state, respirator effort, capillary refill, eye opening, $\mathbb{D}$ verbal response, and motor response. Information was also recorded on the $\overrightarrow{\mathbb{D}}$ use of techniques which are currently used by ambulance staff in Scotland $\stackrel{\square}{2}$ such as oropharangeal airway management, artificial ventilation, oxygen treatment, and cardiac massage.

Further information was collected by accident and emergency medical $\frac{\delta}{0}$ staff on all patients admitted to the resuscitation areas of both hospitals and on a sample of other patients admitted to Glasgow Western Infirmary. This 
information was collected using the same descriptive methods used by ambulance personnel. Additional information was obtained on blood pressure on admission, patient survival, and disposal within the hospital. Whether or not the patient was alive at three months was determined for all patients taken to a resuscitation area and for a sample of all other patients included in the study.

The potential for advanced prehospital care by ambulance crews was assessed for all patients taken to the resuscitation areas. Two members of the study group carried out independent assessments based on information relating to transportation times, components of the triage index recorded both at uplift and on arrival at hospital, and data from hospital records. The assessors were asked to consider the scope for ambulance crews to use the following advanced techniques: intravenous access, defibrillation, endotracheal intubation, chest drainage, administration of naloxone or cardioactive drugs, and the use of a nebuliser and medical antishock garment. Having determined which of these could have been used the assessors then considered whether further intervention could have improved the probability of survival in patients who died within three months of the initial incident. A distinction was made between short and long term survival. Short term survival was defined as survival which was unlikely to extend beyond seven days because of the seriousness of the patient's condition or the existence of an underlying terminal disease. Long term survival was defined as survival for more than seven days. In cases of cardiopulmonary arrest assessments were subject to the constraints that long term survival was less likely in patients over the age of 70 or in patients with evidence of serious underlying disease.

In any case in which there was uncertainty the maximum possible benefit, in terms of patient survival, was assumed. Thus the aim of the assessments was to establish the upper limit of benefit which could have accrued to patients had advanced techniques been used.

Algorithms were established and used by the group members in assessing

\section{Coma}

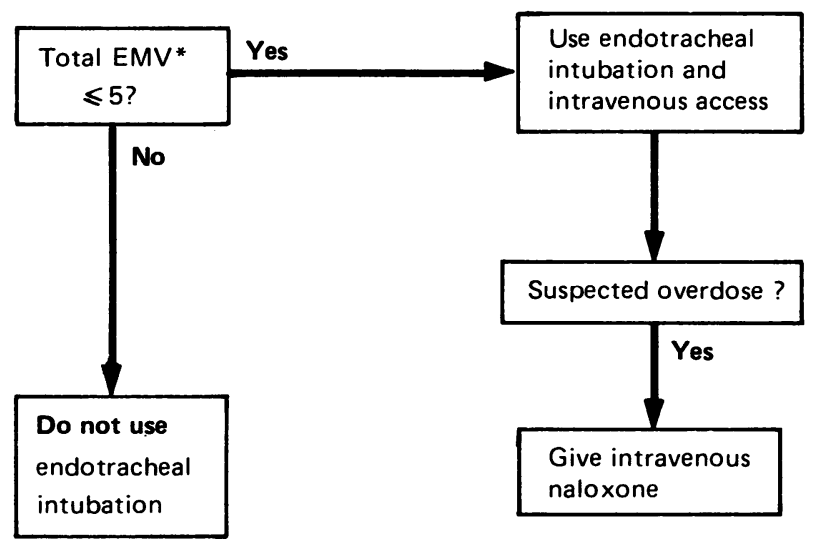

*EMV = combined eye opening, motor response, and verbal response scores from initial ratings

\section{Cardiac arrest ?}

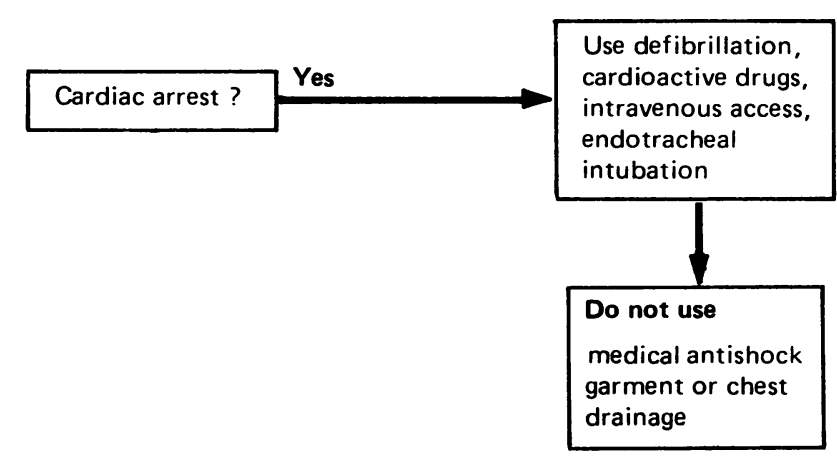

cases of coma, volume loss, and cardiopulmonary arrest, or combinations of these conditions. Figure 1 shows the algorithms.

Results of the initial assessments were collated and disagreements reviewed. All cases in which the initial assessors had disagreed or in which the possibility of benefit to non-survivors had been identified were referred to two additional assessors.

Discrepancies among the four assessors were noted and discussed at panel meetings, at which each had the opportunity to modify his original assessment. The outcomes of the panel discussion could be either that all differences were resolved or that a majority opinion was achieved.

\section{Results}

A total of 20743 patients were admitted to the study from the 26358 patients taken by ambulance to the two accident and emergency departments. The 15245 patients transported in Edinburgh represent $100 \%$ of the patients taken to Edinburgh Royal Infirmary, and the 5498 Glasgow cases represent $49 \%$ of patients taken to Glasgow Western Infirmary during the study period.

Information was recorded by ambulance crews at the time of uplift on $78 \%$ of the patients taken to Edinburgh Royal Infirmary and by medical staff at the time of admission to the accident and emergency department on $28 \%$ of the patients taken to Glasgow Western Infirmary. A total of 1185 patients was admitted to the resuscitation areas of the two hospitals: 701 in Edinburgh (4.60\% of all patients transported) and 484 in Glasgow ( $4.35 \%$ of all patients transported) (fig 2 ). The mean time from the call being received to arrival at hospital for patients taken to resuscitation areas was 30.3 minutes (table I).

Information on outcome available for 3689 patients from both centres (all

\section{Circulation volume loss}

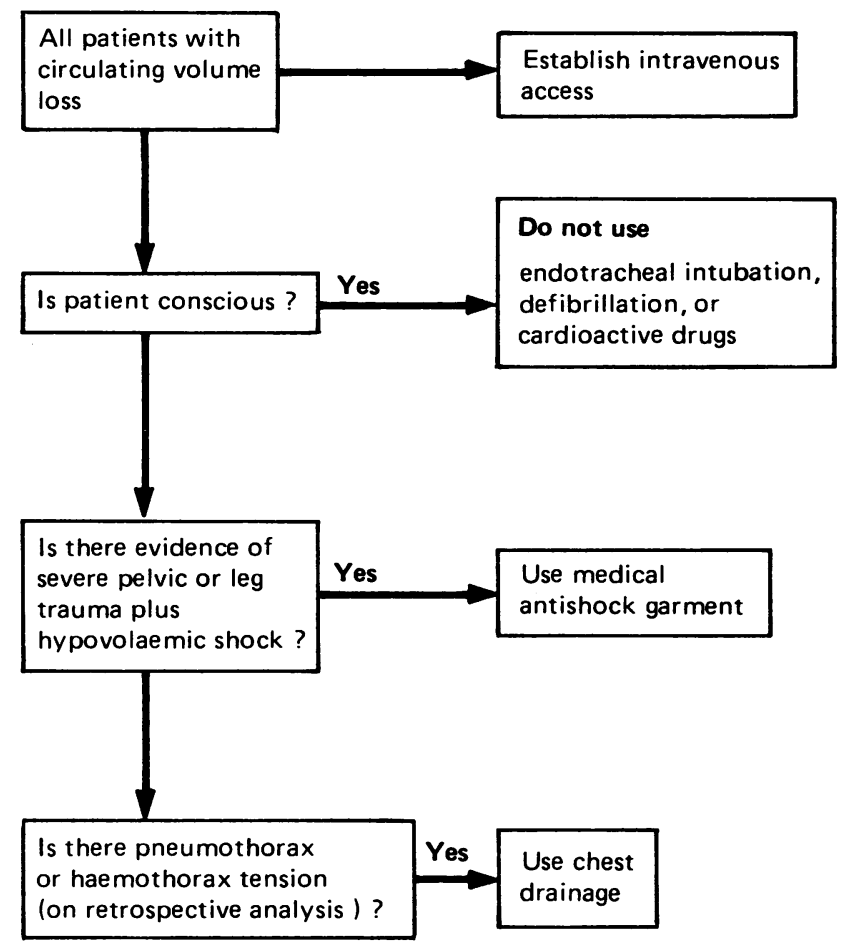


Total number of patients transported as emergency cases

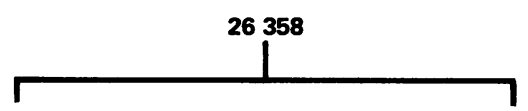

Edinburgh Royal Infirmary Glasgow Western Infirmary 15245

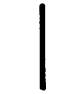

Patients admitted to study

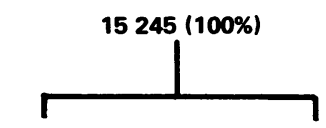

Non-resuscitation cases

Resuscitation cases

701 (4.6\%)

$11113^{*}$

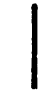

Patients admitted to study

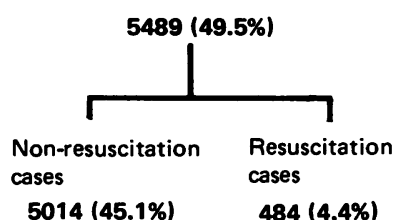

"Estimate

FIG 2-Study populations.

resuscitation cases together with a systematic sample of $12 \%$ of the remainder) was used to calculate estimates of three month mortality for all patients transported by ambulance. The estimated overall three month mortality was $8 \cdot 4 \%(8 \cdot 3 \%$ in Edinburgh and $8 \cdot 5 \%$ in Glasgow).

Thirty eight of the 1185 patients requiring resuscitation were pronounced dead on arrival at the resuscitation areas, 116 died while in the resuscitation areas, and 242 died within three months. The three month mortality for patients admitted to the resuscitation areas was 33.4\% (33.5\% in Edinburgh and $33.2 \%$ in Glasgow). Of the 396 non-survivors, 50 were patients with trauma and 346 were medical emergencies.

For the 1185 patients admitted to the resuscitation area there was agreement between the two initial assessors on both the scope for using advanced techniques and the possibility of benefit to non-survivors in 1095 $(95 \%)$ cases. The remaining 90 cases were referred to the two additional assessors. Further consideration was also given to 88 non-survivors for whom the initial assessors had agreed that the use of advanced techniques could have improved the probability of survival.

Of the 178 cases which were subject to assessment by the panel there were $160(90 \%)$ in which all four assessors reached a consensus on both the scope for using advanced techniques and the possibility of improvements in the probability of patient survival. In 18 cases (10\%) a majority view was achieved after discussion.

Table II summarises the number of cases in which the assessors considered that the various advanced techniques could have been used and the maximum possible benefit, in terms of patient survival, which might

TABLE I- Fourney times of ambulances (from time call received to time of arrival at hospital) for patients admitted to resuscitation areas ${ }^{\star}$

\begin{tabular}{lccccccc}
\hline Time (min): & $0-9$ & -19 & -29 & -39 & -49 & -59 & $\geqslant 60$ \\
No of patients: & 6 & 208 & 428 & 284 & 144 & 40 & 41 \\
\hline
\end{tabular}

^Times not recorded in 34 cases.

TABLE II-Number of cases in which advanced technique could have been used and potential benefits to non-survivors

\begin{tabular}{lccc}
\hline Advanced technique & $\begin{array}{c}\text { Could have } \\
\text { been used }\end{array}$ & $\begin{array}{c}\text { Short term } \\
\text { survival }\end{array}$ & $\begin{array}{c}\text { Long term } \\
\text { survival }\end{array}$ \\
\hline Intravenous access & 1074 & 39 & 52 \\
Medical antishock garment & 21 & 2 & 1 \\
Defibrillation & 137 & 23 & 51 \\
Cardioactive drugs & 164 & 29 & 51 \\
Endotracheal intubation & 358 & 33 & 51 \\
Naloxone & 114 & 1 & 6 \\
Chest drainage & 13 & 0 & 0 \\
Nebuliser & 48 & 0 & 0 \\
Survival from any technique(s) & & 41 & 54 \\
\hline
\end{tabular}

Total number of patients taken to resuscitation areas $=1185$.

Total number of non-survivors $=396$.

In seven cases there was insufficient information to make an assessment have accrued as a result. Forty one of the 396 non-survivors might have survived in the short term as a result of use of one or more techniques and 54 might have survived in the long term. No patients could have survived as a result of chest drainage or the use of a nebuliser, and survival in the long term as a result of using a medical antishock garment was considered possible in only one case. Six patients might have survived in the long term if they had been treated with naloxone.

TABLE III-Number of patients in whom probability of survival in long term could have been improved by use of advanced technique(s) by type of case

\begin{tabular}{|c|c|c|c|c|}
\hline \multirow[b]{2}{*}{ Type of case } & \multicolumn{3}{|c|}{ Long term survival } & \multirow{2}{*}{$\begin{array}{c}\text { Total No } \\
\text { of patients } \\
\text { assessed }\end{array}$} \\
\hline & Edinburgh & Glasgow & Total & \\
\hline Coma & 3 & - & 3 & 102 \\
\hline Volume loss & - & - & - & 32 \\
\hline Coma and volume loss & 1 & - & 1 & 34 \\
\hline Cardiac arrest & 31 & 17 & 48 & 120 \\
\hline Monitor only & - & $2^{\star}$ & $2 \star$ & 87 \\
\hline Other & - & - & - & 19 \\
\hline Unknownt & - & - & - & 2 \\
\hline Total & 35 & 19 & 54 & 396 \\
\hline
\end{tabular}

${ }^{\star}$ Cardiac arrest in ambulance.

†Both dead on arrival at resuscitation area.

Overall, of the 54 patients in whom the use of one or more of the advanced $\infty$ techniques could have resulted in long term survival, 50 were cases of 음 cardiopulmonary arrest, three were cases of coma, and one was a case of $N$ coma and volume loss (table III).

\section{Discussion}

The assessors who appraised the 396 non-survivors admitted to the resuscitation areas attempted to identify the maximum possible benefit, in terms of patient survival, which could have resulted from the use of advanced techniques by ambulance crews in an urban and semiurban area. No assessment was made of morbidity.

Fifty of the non-survivors were cases of trauma. Of these, the study identified only one patient in whom the use of advanced techniques could have improved the probability of survival in the long term.

The equivalent figures for cardiopulmonary arrest were 50 possible survivors from a total of 122 patients. These 50 patients were all under the age of 70 and had no known pre-existing serious disease. This represents the maximum number of lives that might have been saved. The actual number would certainly have been smaller, even if arrangements could have been made to ensure that staff with advanced training and equipment were available when required. In many of the 50 cases survival would have depended not only on the skills of ambulance crews but also on other factors such as the time taken for an ambulance to reach the scene of the incident and the possibility of effective cardiopulmonary resuscitation by a $\widetilde{\sim}$ bystander. In 25 of the 50 cases more than six minutes elapsed between the first call and the arrival of the ambulance.

Before the present study the only systematic attempt to assess the $N$ possible benefits of extended training was a study carried out by Wright, who reviewed the evidence available from existing studies 0 and constructed estimates of the number of lives which could be saved for each continuously staffed accident and emergency $\frac{D}{D}$ ambulance. ${ }^{8}$ Based on these estimates the predicted number of lives $\stackrel{\mathcal{P}}{+}$ which might have been saved among the study population was about 7 72 , of which perhaps 24 would have been cases of trauma and 48 cases of cardiopulmonary arrest. By comparison, our results suggest $\stackrel{\square}{\square}$ that the maximum number of lives saved could have been no more $\mathbb{D}$ than one for cases of trauma and certainly less than 48 for cases of cardiopulmonary arrest.

It is important to explain why the present study provides more pessimistic estimates of improvements in patient survival than the earlier estimates in the case of cardiopulmonary arrest and is $\frac{\bar{b}}{7}$ 
irreconcilable with the earlier estimates in the case of trauma. An important aspect of our methods was the fact that only those patients who did not survive a traumatic or medical emergency under the present system of prehospital emergency care were subject to detailed appraisal. By contrast, studies which are carried out on ambulance services with extended training must overcome the difficulty that the successful use of an advanced technique does not necessarily imply that the benefit in terms of survival is attributable to the extended training. Many of the patients successfully treated with an advanced technique might have survived had only standard techniques been available, a problem to which Wright drew attention when constructing his estimates. ${ }^{8}$ The earlier estimates may have taken insufficient account of this factor.

The results of this study indicate that benefits resulting from the introduction of extended training will be more modest than has been suggested. The nature of local operational constraints, such as transportation times, and factors such as the possibility of cardiopulmonary resuscitation by another citizen may determine whether the introduction of extended training would be worth while. Our results show that the proposition that extended training will always be justified irrespective of local circumstances is unfounded.

\section{References}

1 Mackintosh AF, Crabb ME, Grainger R, Williams JH, Chamberlain DA. The Brighton resuscitation ambulance; review of $\mathbf{4 0}$ consecutive survivors of out-of-hospital cardiac arrest. BrMed f 1978;i:1115-8.

2 Baskett PJF, Diamond AW, Cochrane DF. Urban mobile resuscitation: training and service. Br F Anaesth 1976;48:377-85.

3 Snook R. Accident flying squad. Br Med $\mathcal{F}$ 1972;iii:569-74.

4 Hampton JR, Dowling M, Nicholas C. Comparison of results from a cardiac ambulance manned by medical or non-medical personnel. Lancet 1977;i:526-9.

5 Pantridge JF, Geddes JS. A mobile intensive care unit in the management of myocardial infarction. Lancet 1967;ii:271-3.

6 Department of Health and Social Security. The ambulance service of the future. London: DHSS, 1979. (National Health Service Training and Studies Centre).

7 Champion HR, Sacco WJ, Hannan DS, et al. Assessment of injury severity; the triage index. Crit Care Med 1980;8:201-8.

8 Wright K. Extended training of ambulance staff. York: University of York, 1984. (University of York Centre for Health Economics. Discussion paper No 2).

(Accepted 13 October 1986)

\title{
Portraits from Memory
}

\section{4-Sir Hector Hetherington, GBE (1888-1965)}

\author{
JAMES HOWIE
}

In October 1951 I took up my duties as professor of bacteriology in the University of Glasgow. Sir Hector Hetherington, a renowned university administrator, was the principal and vice chancellor, and I reckoned that my first duty would be to pay a courtesy call on this

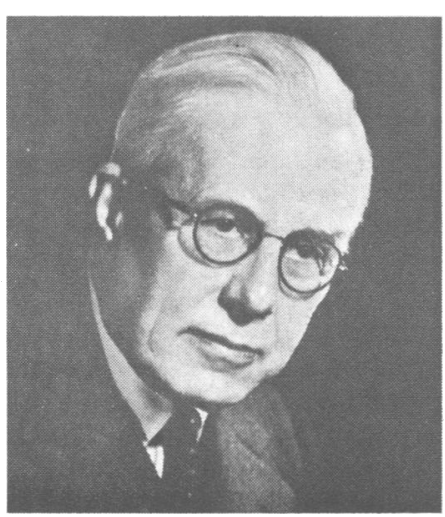

Sir Hector Hetherington. great man. I asked for an appointment from his secretary, Rosemary Noyce, sister of a famous Himalayan mountaineer.

"What's the problem?" she asked. When I explained that there was no problem but that it was simply a matter of arranging to pay a courtesy call she expressed pleased surprise. "That'll tickle him," she said.

At 0830 next day I greeted Sir Hector in his office.

"Sit down laddie," he said. "This old world courtesy is very pleasing. How do you see your job? I know that your accommodation is inadequate. That is true for all new professors."

I outlined the thoughts I had about my commitments, emphasising particularly the institution of the new honours course in

\section{Edinburgh EH13 OBU}

SIR JAMES HOWIE, MD, FRCP

Correspondence to: 34 Redford Avenue, Edinburgh EH13 0BU.
This is the fourth of a series of short articles by Sir James Howie. The complete collection will be published as a book.

microbiology as a science subject and-of course-the programme of research $\mathrm{I}$ had in mind.

"That is very interesting indeed," he said, "but let me tell you that none of this will be your first priority. I hope that people in your department will help you to carry out much of what you have described to me; but none of it will be your first priority. That will be to support the regional hospital board of this new National Health Service. The board has the laudable policy of upgrading the periphery and your subject is one of those in greatest need in the periphery. What you must do is to support the board in every way you can without letting their right policy of upgrading the periphery be accomplished by downgrading the centre. It is a tradition of Scottish university professors that they combine citizenship with their scholarship. That is vital to this National Health Service in Scotland because, outside the teaching hospitals, there is not only far too little but next to nothing of adequate standard. And we are not seeking to shelter under separate boards of governors for the teaching hospitals."

\section{Exhausting and rewarding}

These words were well justified by my experiences during the next 12 busy and happy years that I spent in Glasgow. New recruits were found and trained, academics were pressed into 